\title{
CONCEITO DE FORMA EM FRANCESCO DE SANCTIS
}

\author{
E. Rina M. Ricci
}

Ao redor de 1855-57, Francesco de Sanctis disvincula-se da influência do pensamento de Hegel e começa a elaborar a sua própria concepção artística, como forma. Coloca-se diretamente contra a estética hegeliana da idéia, que procurava encerrar a finalidade da arte na representação da realidade humana e fenomênica dentro de um véu, mediante ab urdas perfeições, perdida no abstrato e no sonho, construindo, assim, uma outra realidade, distilada apenas da imaginação mediante sutis elucubrações mentais.

De Sanctis (1817-1883) sentiu a imposição de uma exigência: a de reconhecer como matéria da arte, não uma realidade, idealizada e evanescente, indefinida e indistinta, mas efetiva, onde a idéia não se perde, e, ao contrário, encontra a sua dimensão e a sua verdadeira razãot de ser. A realidade, portanto, mantida em seu limites, sem transcendências inconsistentes ou deslocada da esfera do próprio artista, que a capta. Essa exigência, para De Sanctis, não significou o rebaixamento quase fotográfico da arte, como fizeram alguns realistas de sua época; nem visualizou a impossibilidade operativa, por parte do artista, em elaborar o mundo sentimental numa atmosfera de férvida imaginação. Distanciou-se de um e de outro extremo e centralizou sea pensamento numa individualização estética significante, vale dizer, numa visão direta e humana da operação artística, que em seu processo formativo não consegue desfigurar ou renunciar às raízes donde brota e tira alimento.

A dicotomia entre forma e conteúdo, de que fôra grande responsável o criticismo francês, transformara em duas entidades inconciliáveis, estes dois aspectos do mesmo ato, ligando a forma a uma série de fórmulas normativas e o conteúdo a uma espécie de condensação lógico-conceitual. A perfeição da forma constituiu-se no maior ideal artístico, entendendo por perfeição, a plasticidade e a simetria dos contornos, ou, na melhor das hipóteses, a proporção harmônica das partes. Se, pois, dentro desse tipo de forma existia ou não um conteúdo, era problema filosófico, não propriamtnte artístico: do pon- 
to de vista estético era entendido como "fictício", porque a fantasia o criava e a fantasia nada tinha a ver com a verdade da história contada.

A esta situação, na segunda metade do século passado, vários movimentos (realismo, naturalismo, expressionismo, etc.) reagiram, cada um, porém, de maneira turbulenta e polêmica, querendo afirmar posições bastante extremadas, não raramente, condenáveis quanto o panlogicismo da estética hegeliana, que reconfirmava, por outros caminhos, a dicotomia racionalista da forma e do conteúdo, mediante a teoria da arte como símbolo e véu da idéia.

De Sanctis, homem de uma agudeza crítica equilibrada, não assume uma posição polêmica e radical. Coloca o problema nas perspectivas e nos limites ambientais em que ele deve naturalmente encontrar seu estudo e solução: frente à vida. A primeira e a mais profunda das realidades é justamente a vida. Mas a vida não é certamente o "ideal", a idealização abstrata do real. Ela é o "vivente"; é o que vive numa unidade inscindível dos seus elementos. Neste conceito alicerça-se a teoria desanctisiana da forma. A questão não é colocada, portanto, entre o real empírico de um lado e o ideal abstrato do outro. Ele concentra-a, ao contrário, sobre aquilo que está entre essas duas polaridades, sintetizando-as. "Matéria da arte, diz De Sanctis, não é o belo ou o nobre: tudo é matéria da arte, tudo o que é vivo: só o que é morto está fora da arte. Por isso, a base da arte, se me é lícito imitar Terêncio, é este lema: Sou um ser vivo: nada do que é vivo é estranho ao meu coração" (1).

Forma, conceqüentemente, é, acima de tudo, síntese expressiva do vivente: aspecto exterior e interior identificados numa indistinção de factibilidade estética, pois ambos reciprocamente sustentam-se como alma e corpo, quando existe a vida. A forma "não é a priori, continua o autor, não é algo que possa subsistir por si, diversa do conteúdo. ela, antes, é engendrada pelo conteúdo, ativo na mente do artista: tal o conteúdo, tal a forma" (2).

Nos famosos Saggi Critici a eliminação da dictomia forma-conteúdo torna-se definitiva e a teoria da inseparabilidade dos dois elementos assume maior extensão esclarecendo que o próprio conteúdo inexiste sem a forma. Por isso a frase anterior "tal o conteúdo, tal a forma" admite a recíproca: - "Quando o conteúdo vive e move-se

(1) - Saggi Critici, a cura di L. Russo, vol. III, p. 324.

(2) - Op. cit., vol. II, p. 306. 
na mente do artista ,torna-se forma, a qual é, portanto, o próprio conteúdo enquanto é arte" (3).

E' ocioso sublinhar que um conceito deste tipo elimina qualquer possibilidade de retorno a teorias que poderíamos classificar de hedonistas no sentido que procuram, na arte, a delicadeza dos contornos, a suavidade dos traços, a plasticidade das linhas, a simetria das partes, enfim, o "gozo" estético, o prazer. "O prazer é individual, mutável e deriva da sensibilidade. O belo, ao contrário, é absoluto. $\mathrm{O}$ primeiro fala unicamente aos sentidos, o segundo por meio dos sentidos e da fantasia e exige a inteligência" (4). O eixo está deslocado: De Sanctis visa à organicidade simétrica e semântica da obra artística, portanto, à vida em sua efetiva operação estética: forma, não como arcabouço, andaime, moldura vistosa em que, a um certo momento, se insere algo, chamado conteúdo. Assim, como nos seres vivos a organicidade constitui a própria estrutura material e anímica, arsim a forma estabelece a propriedade existencial da arte, ao dar unidade estrutural aos elementos que compõem a obra. $O$ conceito está a demonstrar que no produto artístico deve-se encontrar presente o homem com toda a sua problemática, as suas aspirações, as suas possibilidades inventivas, aberto a qualquer tipo de experiência, árbitro inconteste do seu trabalho, agindo fora do "ideal fantasioso e retórico" e inspirado pelo "ideal positivo e vivo" que "se encontra na realidade" $\mathrm{O}$ artista, "quanto mais se aproxima do real, se espelha e se imerge nele - diz De Sanctis - mais eleva-se, no homem, o elemento humano e demonstra mais força" (5).

Mas o realismo invocado pelo autor, não é por exemplo, o de E. Zola, escritor a quem De Sanctis admirava muito e dedicou um dos melhores seus ensaios críticos. Justamente no "Apêndice" a uma conferência sobre Zola e l'Assommoir (1879), o crítico italiano define a sua maneira de entender o realismo: "A sua sub tância é esta, que na arte precisa dar uma parte ampla às forças naturais e animais do homem, afastar o rêve e substituí-lo pela ação. $\mathrm{O}$ realismo que se parece com uma orgia, é poesia de velhos impotentes e viciosos.

E a forma do realismo, é esta, que seja corpulenta, clara, concreta, porém que dentro dela transpareçam todos os fenômenos da consciência. $O$ homem deve traduzir em ação, não em palavras, o que pensa. Mas em sua ação há de manifestar-se o seu pensamento. Esta é a forma objetiva, a vida das coisas. $\mathrm{O}$ artista é como um gran-

(3) - Ibidem.

(4) - Teoria e Storia della Letteratura, Bari, Laterza, 1926, vol. II, p. 49.

(5) - Saggi Critici, vol. III, p. 296. 
de ator, que esquece a si mesmo e reproduz o personagens da maneira que a natureza o formou. " (6). Trata-se, portanto, de um realismo que não recusa o ideal, desde que o ideal não se coloque como repulsa vazia da contingência. Se, porém, é o ideal da realidade, vale dizer, da concretude em toda a sua extensão, então ele torna-se elemento fundante da forma. Logo da arte.

A forma, poderíamos acrescentar, enquanto não é idéia (visão), não é também retrato direto das coisas: concilia o ideal e o real. Se ela não preexiste já pronta, como arquétipo, não significa que não possa vir a ser, como tipo, através do efetivo modelamento permitido às possibilidades humanas, porque, em sua dimensão de liberdade, o homem consegue colher e exprimir o ideal nas coisas como em seu coração.

A conciliação leva a outra espécie de ideal: "do seio inconsciente da natureza brota o ideal humano, como água da nascente" (7). Então do conceito de forma como síntese expressiva do vivente, o autor passa, com clara e progressiva elucidação, ao de forma como ideal humano, onde o ser vivente por excelência é o homem e não o animal, a planta, as formas sempre repetidas da natureza. "O ideal - continua De Sanctis - não nasce da vida artística sobreposta e misturada com a vida natural. O ideal encontra-se nas coisas, das quais porém emergem luzes e faíscas de sentimentos humanos" (8).

Evidencia-se que o conceito de forma não postula ou vislumbra de maneira nenhuma o de técnica, que o autor italiano deixa ao arbitrio completo do artista. Escapa igualmente à posição platônica por não ser éidos, e à aristotélica, por não ser praxis. (Entenda-se o termo na mais correta acepção do estagirita). Nem se aproxima do velho conceito de mímesis, porque a imitação da natureza é "repetição dos objetos que se encontram na natureza; neste caso a arte seria inútil: aquilo que se vê num quadro ou num poema pode ser admirado, ainda melhor, em nossos jardins e em no:sas casas" Consequentemente a imitação (mímesis) "pode produzir obras técnicas, nunca obras de criação" (9). Sanctis?

Qual, então, a natureza e a qualidade da forma proposta por De

(6) - In Saggi Critici, vol. IIl, pp. 336-7.

(7) - Op. cit., p. 329 .

(8) - Ibidem.

(9) - Teoria e Storia della Letteratura, pp. 47 e 49. 
Um aprofundamento neste sentido seria extremamente importante, mas o autor não se preocupou em processá-lo, avesso como era a conceituações rigorosas e a sistematizações rígidas. Isto, entretanto, não significa que a teoria desanctisiana se perca na indistinção e possa naufragar especulativamente.

O fato de assimilar a forma com o "vivente" (10), explicitado como ideal humano, permite inferir que, se De Sanctis não nos deixou uma doutrina elaborada em seus detalhes filosóficos, deu início, porém, a uma concepção nova, de que muito se beneficiariam a estética e a crítica sucessivas, na Itália e fora deste País. Mas nos permite também tirar uma conclusão abrangente, para nós bastante clara dentro deste conceito de forma, aparentemente tão pouco rigoroso: o problema da arte e da crítica não pode ser impostado numa indagação daquilo que a arte e a crítica devem ser (problema deontológico), mas no efetivo reconhecimento daquilo que elas são, sem pretender impor-lhes nenhuma determinação ou finalidade.

Esta conclusão talvez pareça confirmar o matiz de indeterminação que, para alguns, encontra-se na teoria do De Sanctis. Na verdade abre o caminho para visualizar o problema estético em bases mais reais e científicas porque recusa as abstrações, o apriorismo, as explicações fantasiosas e valoriza a obra artística como um organismo vivo. E transforma, por completo, a perspectiva crítica, pois a forma de um organismo vivo obriga a análises orgânicas, que, por sua vez e natureza, obrigam a desconfiar sempre de métodos e critérios laboratoriais, idôneos para explicar os fenômenos químicos e físicos, não o processo e o fato artísticos.

Os fenômenos da natureza, sem dúvida, são imunes ao "pathos"; os artísticos, ao contrário, vivem do "pathos", onde se afundam as raízes da individualidade e da originalidade da obra de arte.

Nenhuma abordagem crítica em campo literário poderá deixar de lado esse aspecto fundamental sem correr o risco de cair em esquemas ou em equívocos, em alquimias verbais, ou, pior ainda, em elucubrações pseudo-estéticas e pseudo-científicas. "A crítica perfeita, adverte De Sanctis, é aquela que concilia, numa síntese harmoniosa, esses diferentes momentos. O crítico deve apresentar o mundo poético reconstituído e iluminado com plena consciência e de tal maneira que a ciência perca, para esse mundo, o seu aspecto doutrinal 
e se torne como o olho que vê os objetos sem ver a si mesmo. A ciência, enquanto ciência, é filosofia, não crítica" (11).

Assim o autor indica mais um caminho que a crítica não pode trilhar; aquele percorrido justamente pelos críticos seus contemporâneos.

"Os diferentes momentos" que se encontram na obra de arte são constituídos pelas diferentes experiências estéticas ali insertas e vivificadas pela forma. Captá-ios e apresentá-los numa síntese harmoniosa - ou, gostaríamos de acrescentar, na rica autenticidade do seu valor - é, sim, a tarefa suprema do crítico. Mas com objetividade, sem duvidosas interpretações pessoais para re-criar o tom ou, como já se dizia naqueles tempos, a atmosfera poética. De Sanctis exige a reconstituição, vale dizer, a revelação autêntica e total do mundo poético, mantido dentro da configuração em que o artista o elaborou, sem comentários exegéticos fantasiosos ou eruditos ou psicológicos. Os fantasiosos sobrepõem-se ao poeta e, em lugar de uma crítica, oferecem um subproduto poético, uma subpoesia, falsidade emotiva, capaz apenas em satisfazer o gosto e as oscilações sentimentais do leitor, não para evidenciar a beleza da obra. Os eruditos acumulam ao redor e sobre a composição poética um acervo de noções, até importantíssimas, mas que impedem a reconstituição do mundo poético. Mais ainda: o submergem numa selva de dados e de informações onde o poético se perde ou se depaupera. $O$ autor demonstra particular adversão aos comentários psicológicos. Ele tinha diante dos olhos a famosa teoria, muito seguida em 1700 (Condillac, Buffon etc.), que colocava na sucessão das faculdades psíquicas do homem (intelecto, memória, fantasia) a raiz e a distinção dos gêneros puros: o lírico, o épico, o dramático, o didático, o fantasioso. "O defeito do sistema psicológico, diz De Sanctis, é o de conceber as faculdades humanas como estacionárias. Vico, porém, já censurou esta doutrina. Se as faculdades humanas fossem estacionárias, por que o poema épico foi possível na época de Dante e agora não? Por que a lírica foi impossível em 1500, e agora é possível? E por que, então, criam-se sempre novos gêneros? as mudanças das sociedades humanas, os tempos, os lugares, as necessidades é que modificam as faculdades humanas e, com estas, os gêneros; a produção lírica ou épica depende de tudo isso e não das faculdades humanas em abstrato" (12).

(11) - Op. cit., vol. II, p. 87.

(12) - Teoria e Storia della Letteratura, pp. 125-6. 
Se as faculdades humanas não são estacionárias e não se encontram nelas as origens dos gêneros em que a produção literária se efeliva, é evidente que a crítica, ao examinar um texto, não pode invocar as imponderáveis situações psicológicas do autor para explicar o gênero da sua obra ou o mundo poético que está contido nela. Este, uma vez fixado, é constante e permanente insubmisso a qualquer alteração (social, moral, estética etc.) sucessiva. Una situação psicológica poderá ser - ou propiciar - uma condição estética. Admite-. se, inclusive, que consiga determinar o ato estético, não, porém, o fato artístico, que, para De Sanctis, é a forma, por sua vez (não devemos tsquecê-lo), "uma coisa e não uma idéia" O crítico deve visar a esta para desvendar o valor que de maneira alguma se encontra na ocasionalidade que por ventura o fixou e, sim, em sua valiosidade: em si e por si. E permanece inalterado. A Ilíada será sempre a Ilíada, com ou sem Homero. Com ou sem a Guerra de Tróia .

Os diferentes fatores que se possam encontrar na obra (históricos, sociológicos, filosóficos, piscológicos, morais, políticos etc.) formam apenas o material que o artista emprega ao elaborar a forma. E "a grandeza do poeta não está nos materiais que emprega, mas na fusão orgânica que fizer deles" (13). Caso a crítica coloque em destaque os materiais, nada acrescentará à valiosidade da obra; talvez o critério sirva para ocultar ou falsificar o mundo poético, tirando ou destruindo a "fusão orgânica", ao salientar pressupostas preocupações ou estados psíquicos do artista.

De Sanctis foi explícito contra processos críticos desta espécie, que buscam menos a beleza efetiva e operante do que as justificativas, as fontes, os momentos psicológicos (quando morbidamente não vão atrás dos patológicos) que, se presume, possam ter motivado a obra. E' uma crítica que "julga frequientemente a priori, opera por normas pré-concebidas, pelas quais tudo mede" " .mal ela começa a falar num trabalho e, logo, ouve-se citar dignidade, ordem, cecoro, elegância, pureza, finito e infinito, real e ideal, literatura social, histórica, filosófica, ou que o poeta é pintor, escultor, músico; ou, finalmente, idéia e verdade, bom e belo" (14).

E' uma crítica interessada em definições e medições para pronunciar, sentenciosamente, juízos estéticos mediante o evidenciamento das partes e não do todo, dos componentes e não da composição ou validando o juízo estético com juízos de outra natureza. Ela é incapaz

(13) - Saggi Critici, vol. I, pp. 18-19.

(14) - Ibidem, vol. II, pp. 106-107. 
de colher o essencial, perde-se nos detalhes e eleva o aspecto didático ou meramente transitório e subordinado a coeficiente determinador de valor, criando uma série de categorias que repugnam à poesia, que não é nem pura nem impura, nem finita nem infinita, nem filosófica, nem social, nem política etc. A composição poética é ou não é forma: é ou não é arte.

Entre as categorias que uma crítica dese tipo consagra há, ainda aquela moral, a pior de todas. Ela submete a arte ao serviço não propriamente da norma universal, já ínsita na natureza, mas de interesses disfarçados em lei moral. E assim, acerca de um trabalho, ela "aprova ou condena segundo que este é bom ou mau, verdadeiro ou falso" (15), em base a uma concepção de moralidade.

Em todos esses casos a crítica procura e valoriza o conteúdo conceitual, não, a forma. Mas o "pensamento, enquanto lógico, está fora da arte" porque "a humanidade pensa sempre, mas pensa ora adorando, ora imaginando, ora operando, ora pensando" e o poeta "não deve, não pode pensar, senão com a imaginação" (16). Eis então a tarefa do crítico: colher o pensamento imaginativo do poeta, donde a forma nasce pelo ato de criação.

Para não cair num equívoco bastante fácil, será necessário esclarecer que o pensamento imaginativo não se identifica com a capacidade de arquitetar ab tratezas sutis, jogos de sons e palavras, conlbinações gritantes de figuras retóricas, como fizeram os poetas barrocos. Trata-se de um pensamento não empenhado em transformar, por exemplo, a metáfora (de que a poesia vive) no metafórico, o grande no grandioso, o estupendo no estupor, o maravilhoso no impacto alucinante, isto é, o instrumento expressivo no próprio objeto de expressão, matando o poético na poesia .

A arte, sem dúvida, para De Sanctis, é figuração enquanto é apercepção da consciência, ainda fora do momento reflexivo. Importante é, entretanto, o que a consciência assume, como o assume e a sucessiva elaboração do material assumido. Em outros termos: a consciência pode receber mil impressões que lhe sugerem abstrações desligadas da realidade, e a impulsionam a inventar acrobacias mentais obedecendo a uma fantasia fertil, mas não é esta a figuração artística indicada pelo autor Por faltar-lhe a representação formal, não viveu na mente do artista como pensamento (elaboração) imaginativo para que se verificasse a síntese orgânica e o conteúdo se tornasse forma e a forma conteúdo.

(15) - Ibidem.

(16) - Pagine Sparse, a cura di Benedetto Croce, Bari, Laterza, p. 16. 
A metáfora não é propriamente uma figura retórica, mas uma figuração poética, se ela se transforma em fim de si mesma passa a simples jogo de analogias, pueril e vazio, como o de uma charada, iinguagem obscura que estimula o sentido divinatório, não certamente o poético. A metáfora é um discurso rápido feito pela imaginação, uma faísca que ilumina com a mesma palavra dois conceitos. Ela, por esse caráter, é muito própria da linguagem poética, ou, se quisermos, do discurso que o pensamento imaginativo usa. Mas não cessa de ser um recurso, um meio, uma combinação engenhosa, válida e maravilhosa somente quando, sem sair da sua função instrumental, serve a formar a forma e não a colocar em evidência o estupor, o impacto, o grandioso, o maravilhoso, que, na melhor das hipóteses, podem ser atributos bastante acessórios da obra artística.

Ora, colher o pensamento imaginativo não significa colocar em destaque, por exemplo, o estilo metafórico do artista, nem a grandeza ou a beleza ou a eficácia das metáforas empregadas. Colher-se-ia um aspecto sem dúvida atraente, não, porém, essencial: evidenciar-se-ia a habilidade arquitetural do artista, não a "síntese expressiva do vivente", que, na obra realmente poética, constitui a força e a perenidade da mensagem. Quando Homero define Afrodite como "anadiomene", a nascida do mar, não resta dúvida que a metáfora é maravilhosa e eficaz, mas nem por isso ela consegue, igualmente, mostrar a forma do poema homérico. A mensagem do imortal poeta grego supera a beleza das metáforas que ele emprega para transmiti-la: é a forma que permite ver a obra como um organismo vivo, superando os séculos, os momentos históricos e ambientais, as distâncias de crenças políticas e re'igiosas, as diferenças de usos e costumes, mentalidade e língua. E a apresenta continuamente atual, mina riquíssima de humanidade.

A forma, concluiremos, é síntese do vivente que sempre indica os limites do ideal. E' conciliação do ideal e do real, operada pelo pensamento imaginativo ao destrui-los como polos opostos para vivificá-los no encontro criador, por meio do qual, a arte nasce e se conserva num seu mundo específico, tranquila e serena, acima de toda dialética.

Se a crítica literária não pode ser deontológica aprioristicamente, entretanto, pela natureza do objeto que indaga, não pode desconhecer a tarefa que se lhe impõe. Da natureza do objeto indagado desponta, ao contrário, também a sua natureza e será uma crítica formal, não no sentido externo, mas interno, de totalidade e não de partes, de um ser vivo e não de um cadáver. 